\title{
ANCA-ASSOCIATED VASCULITIS AS A CAUSE OF FEVER OFUNKNOWN ORIGIN IN AN ELDERLY PATIENT
}

\author{
Mariana Oliveira Miranda ${ }^{1, \star}$, Gustavo Luiz Behrens Pinto ${ }^{1}$, Renata Borges de Lima ${ }^{1}$, Maria de Lourdes Castro de Oliveira \\ Figueiroa ${ }^{1}$, Alisson Regis de Santana ${ }^{1}$, Viviane Leal Novais ${ }^{1}$, Victor Pereira Mattos ${ }^{1}$, Mittermayer Barreto Santiago ${ }^{1}$
}

1.Universidade Federal da Bahia, Salvador (SP), Brazil.

*Corresponding author: marianam_o@hotmail.com

\section{BACKGROUND}

ANCA-associated vasculitis (AAV) are systemic inflammatory diseases characterized by necrotizing vasculitis that preferentially affects small-caliber vessels. In addition to manifestations related to vascular involvement (skin, lung, and kidney lesions, among others), patients with this condition may also develop systemic symptoms such as fever and weight loss related to the inflammatory process. The authors describe an elderly patient with a fever of unknown origin with the final diagnosis of AAV.

\section{CASE REPORT}

A 70-year-old white male, previously healthy, was admitted to a tertiary hospital complaining of fever for about 7 months. Daily, predominantly at night, it was persistent with chills and associated with inappetence, asthenia, and significant weight loss. The patient denied other symptoms. Besides fever $\left(38^{\circ} \mathrm{C}\right)$ the rest of the physical examination was unremarkable. However, during his hospitalization, he developed a purpuric skin rash in his legs and complained of large-joints arthralgia. Initial laboratory work-up revealed white blood cell count $214 \times 109 / \mathrm{L}$; hemoglobin, $9.1 \mathrm{~g} / \mathrm{dL}$; serum creatinine $1.1 \mathrm{mg} / \mathrm{dL}$; serum protein electrophoresis revealed a polyclonal hypergammaglobulinemia; urinalysis unchanged. Bacterial, viral and fungal infections were excluded. Antinuclear antibody was positive 1/640, dense fine speckled cytoplasmic pattern. Anti-Jo-1 and anti-ribosomal P antibodies were negative. ANCA was positive $1 / 320$ perinuclear pattern. Skin biopsy evidenced small and medium vessel vasculitis, with associated dermal coagulation necrosis. Intravenous methylprednisolone $1 \mathrm{mg} / \mathrm{kg} / \mathrm{day}$ was started, and the patient evolved with cessation of his fever, joint pain, and loss of appetite, and resolution of the skin lesions.

\section{CONCLUSION}

Granulomatosis with polyangiitis, eosinophilic granulomatosis with polyangiitis and microscopic polyangiitis are the classical AAV. They have an annual incidence of about 10 to 20 cases per 1,000,000 inhabitants. There is a predilection for white populations, and they are more prevalent in men. Clinically, they may present a wide spectrum of clinical manifestations, usually involving the sinuses, lungs, kidneys, eyes, skin, and peripheral nerves. Constitutional symptoms are extremely rare when manifested in isolation. Fatigue, fever, and weight loss are the most evident. The authors draw attention to a case of AAV who did not fulfill diagnostic criteria for any specific AAV, whose clinical presentation was a long-term fever of unknown origin.

\section{KEYWORDS}

ANCA-associated vasculitis, Necrotizing vasculitis, Fever. 